\title{
Quality Assurance in Education
}

\section{Emerald Article: Investigation of Malaysian higher education quality culture and workforce performance}

\author{
Hairuddin Mohd Ali, Mohammed Borhandden Musah
}

\section{Article information:}

To cite this document:

Hairuddin Mohd Ali, Mohammed Borhandden Musah, (2012),"Investigation of Malaysian higher education quality culture and workforce performance", Quality Assurance in Education, Vol. 20 Iss: 3 pp. 289 - 309

Permanent link to this document:

http://dx.doi.org/10.1108/09684881211240330

Downloaded on: 30-06-2012

References: This document contains references to 36 other documents

To copy this document: permissions@emeraldinsight.com

Access to this document was granted through an Emerald subscription provided by UNIVERSITI PUTRA MALAYSIA

\section{For Authors:}

If you would like to write for this, or any other Emerald publication, then please use our Emerald for Authors service.

Information about how to choose which publication to write for and submission guidelines are available for all. Please visit www.emeraldinsight.com/authors for more information.

\section{About Emerald www.emeraldinsight.com}

With over forty years' experience, Emerald Group Publishing is a leading independent publisher of global research with impact in business, society, public policy and education. In total, Emerald publishes over 275 journals and more than 130 book series, as well as an extensive range of online products and services. Emerald is both COUNTER 3 and TRANSFER compliant. The organization is a partner of the Committee on Publication Ethics (COPE) and also works with Portico and the LOCKSS initiative for digital archive preservation. 


\title{
Investigation of Malaysian higher education quality culture and workforce performance
}

\author{
Hairuddin Mohd Ali and Mohammed Borhandden Musah \\ Institute of Education, International Islamic University Malaysia, \\ Kuala Lumpur, Malaysia
}

\begin{abstract}
Purpose - The purpose of this study is to examine the relationship between the quality culture and workforce performance in the Malaysian higher education sector. The study also aims to test and validate the psychometric properties of the quality culture and workforce performance instruments used in the study.

Design/methodology/approach - A total of 267 academic staff from the International Islamic University Malaysia completed the survey questionnaires. A principal component analysis (PCA) technique was performed to extract the underlying factors, followed by the application of confirmatory factor analysis (CFA) to test factorial validity of the constructs.

Findings - The analysis yielded a nine-factor-indexed quality culture construct, while the workforce construct constituted two factors. The findings of the study postulate statistically significant correlation between quality culture and workforce performance.

Practical implications - The findings of the study suggest that a quality culture initiative can be used effectively in the context of the Malaysian higher education sector to enhance academic staff performance.

Originality/value - The results are important since there have been few published studies on quality culture that examine its effects on academic staff performance in the Malaysian higher education sector.
\end{abstract}

Keywords Quality culture, Malaysia, Workforce performance, Higher education,

Psychometric properties

Paper type Research paper

\section{Introduction}

Attaining quality is a major goal of any organisation, be it an educational institution, manufacturing or other business enterprise. Quality culture, among other quality paradigms, was initiated to attain educational internal quality goals. The concept of quality management, in general terms, can be traced back many decades, including to the ancient civilisations. However, it did not receive much attention in the academia until more recently. Over the years, particularly in the 1980s, practitioners and academicians such as Deming (1986), Crosby (1979) and Juran (1988) among others have shown specific interest in quality management. Thereafter, the quality management movement evolved through five major different complementary paradigms, namely; quality circles, quality control, quality assurance, total quality management and quantum quality (Miller, 1993). Each of these par\{QAE $\}$ Articles/148610/148610.3dadigms has its own dimensions where quality management is looked on from a dichotomous perspective. However, these quality paradigms were subject to failure (Sinclair and Collins, 1994) to a certain extent in some

higher education quality culture 
QAE 20,3

\section{0}

areas due to uncertainty about the prevailing quality management practices (Harvey, 2009). Consequently, quality culture was introduced to provide a comprehensive approach to quality sustainability with special reference to institutions of higher education (European Universities Association [EUA], 2002-2006).

\section{Quality culture}

Quality culture as a paradigm in the education context covers those elements of organisational culture that have the strongest impact on the quality of teaching. It establishes an on-going process of improvement, in which it holds all of the organisational community accountable for sustaining a favourable work environment that leads to organisational excellence (Trewin, 2003). It is unique in quality culture perspective, that quality is held as a process that can be operated through evaluation and measurement.

Quality culture is defined as the overall attitude of an institution, which focuses on the concept of quality and applies it to all aspects of its activities. In other words, an institution as a whole has embraced quality in every element of functionality that enhances continuous improvement. It is a learning culture in which all members of an institution are involved in a self-critical assessment and improving culture in which all of the workforce of the institution is fully engaged in all activities carried out by the institution (Rose as cited in Muresan, 2008; Trewin, 2003).

Various factors contribute to the development of a quality culture. The findings of an early study on quality culture in the industry found seven factors (senior management leadership, employee involvement and empowerment, customer focus, supplier partnership, teamwork, effect of chief executive officer (CEO) and open corporate culture) affecting the development of a quality culture (Adebanjo and Kehoe, 1999). Recently, a study of the factors influencing the strategic development of a quality culture at Eastern Schools of the Office of Vocational Education Commission in Thailand found nine factors (manager leadership, management by fact, strategic plan, decentralisation, continuous self-development, organisational commitment, teamwork, customer care and continuous improvement) affecting the development of quality culture. These factors of quality culture accounted for 72.413 per cent of the variance explained (Tungkunanan et al., 2008). Similarly, Johnson (2000) found nine factors including top management support for quality, strategic planning for quality, customer focus, quality training, recognition, empowerment and involvement, quality improvement teamwork, measurement and analysis and quality assurance influencing the development of a quality culture. This establishes a workplace where all employees are clearly aware of the importance of quality and continuous improvement, and that their role in quality activities is indispensible. A study that was conducted to assess the vitality of a quality culture concluded that there is enormous need for quality culture in organisations (Bowen, 1996).

Quality culture has a significant influence on the institutional settings where it is being implemented. Empirically, a strong influence of quality culture on quality of teaching has been established (EUA, 2002-2006; Kowalkiewicz, 2006). Furthermore, quality culture largely determines the quality of teaching exercised by the faculty members of institutions of higher learning (Harvey, 2009). A comparative study, which investigates companies implementing total quality programmes and non-total quality programmes, found that companies, which had developed a quality culture, noticed 
significant levels of improvement in their total quality programmes. On the other hand, companies that had experienced difficulties with quality culture change were unable to generate ideas that could propel continuous improvement and long-term development (Adebanjo and Kehoe, 1999).

However, according to Ehlers (2009), there is a dearth of fundamental research and conceptual understanding of the phenomenon, though understanding of quality as part of organisational culture seems to have attained some importance recently. Newton (2006) and Vettori et al. (2006) found that the traditionalism of quality in spheres of academic activities and the factors calling for new approach are both clearly evident in today's higher learning institutional settings. This change, according to Diana (1994), is due to the shift from an elite educational system to a mass educational system. Taking these arguments highlighted above into account, this study hypothesises that:

H1. Quality culture positively influences faculty's motivation in the Malaysian higher education sector.

H2. Quality culture positively influences faculty's work performance in the Malaysian higher education sector.

H3. Quality culture positively influences faculty's job satisfaction in the Malaysian higher education sector.

H4. The responses to quality culture can be explained by nine first-order factors and three second-order factors.

H5. The constructs of quality culture are valid and reliable.

Quality culture practices in educational institutions can be enhanced through various means among which faculty members are the most influential. Achieving quality in faculty members' performance requires institutions of higher learning to have advanced and dynamic staff training programmes and a quality culture in place. This is done in order to respond quickly and appropriately to rapid changes in the field of education and staff needs.

\section{Workforce performance}

An important component of human resource management is the development and retention of an efficient and qualified workforce. An effective workforce leads to effectiveness of the organisation and high productivity. According to Horn and Fichtner (2003), a qualified workforce together with other organisational variables not only contribute to an organisation's success per se, but also contribute to the national tax base, keeping the company's ability to remain effective in a highly competitive business world.

In fact, the workforce is extremely important if efficient performance is to be accomplished. Meanwhile, a simple miscommunication between managers and employees may lead to unexpected frustration or consequences for workforce performance, labour turnover and intention to leave among others. As such, Papis (2006) posits that the significance of understanding the workforce is very important if organisational objectives are to be realised. A study that surveyed Scottish hostel assistants pertaining to the importance of understanding the workforce suggests that a balanced environment, coupled with mutual understanding of the workforce is

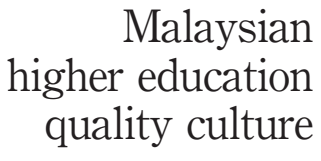

291 
QAE 20,3

292 imperative if the task, organisational objectives and business achievements are to be accomplished efficiently (Papis, 2006).

The Malaysian workforce, as in other progressing countries, is considered to be young compared to developed nations such as Japan, USA, the UK and others. The statistics for 1999 revealed that over 68 per cent of the Malay workforce and 58 per cent of the Chinese workforce were under the age of 34 . The literature revealed that workforce performance is influenced by motivation, work performance and job satisfaction. As such, this study hypothesises that:

H6. Workforce performance in the Malaysian higher education sector is explained by these three factors.

H7. The constructs of workforce performance are valid and reliable.

\section{Method}

Participants

A sample of 267 (13.86 per cent) respondents was selected from the total population (1926) of the International Islamic University of Malaysia academic staff. The sample size (267) was determined by considering the confidence interval of 95 per cent and margin of error at \pm 6 per cent as suggested by Vockell and Asher (1998) and Yamane (1967). The respondents were randomly selected and participated voluntarily in answering the survey questionnaires, which were distributed to the respondents during their free time. They were asked to express their level of agreement or disagreement with the propositions in the survey instrument.

\section{Instrument}

The study used the survey questionnaire in the process of investigating the relationship between quality culture and workforce performance. Excluding the demographic information of the respondents, the questionnaire consisted of 83 items (Adebanjo and Kehoe, 1999) of which, 61 items constituted the quality culture construct and 22 items comprised the workforce performance construct. The researcher constructed the items of workforce performance through extensive analysis of the related literature on workforce performance at institutions of higher learning. Due to the unavailability of an appropriate questionnaire on workforce performance, the researcher developed the propositions of this construct guided by the available literature.

The questionnaire is composed of close-ended statements used to determine the phenomenon that the research aimed to investigate. Furthermore, it comprised two major sections. Section one, formed of eight items, which requested respondents to provide general demographic information such as gender, age group, race group, marital status, religion, academic position, teaching experience and monthly income. Section two, comprised two major constructs the first construct, consisting of 61 items, investigated quality culture in the Malaysian higher education sector. The second construct, consisting of 22 items, examined academic staff performance in the Malaysian higher education sector. A five-point Likert type scale was employed for data collection. The scale is interpreted as: $1=$ very strongly disagree, $2=$ strongly disagree, $3=$ disagree, $4=$ not sure, $5=$ agree, $6=$ strongly agree and $7=$ very strongly agree. 
Prior to data analysis, the quality of the data collected needed to be examined (Meyers et al., 2006; Kline, 2011; Tabachnick and Fidell, 2007). This enabled the data accuracy, missing data issues, outliers, and statistical assumptions among others to be assessed.

\section{Data analysis and findings}

The data collected were analysed following three-step procedure. First, principal component analysis (PCA) using SPSS version 17.0 software was used to test the factors that underlie the constructs under study. This was then followed by application of structural equation modelling (SEM) using AMOS version 17.0 software to test the structural models of the constructs (Arbuckle, 2008). Finally, assessment of construct validity through average variance extracted (AVE) and construct reliability through composite reliability index (CRI) were performed.

\section{Respondents' demographic information}

The accuracy of the dataset is often assessed through code and value cleaning using descriptive frequencies. The results of the frequencies indicated that $(n=109$, 56.2 per cent) of the respondents were male academic staff, while ( $n=85,43.8$ per cent) were female academic staff.

With reference to respondents' age group, the analysis showed that the majority of respondents were aged between $36-45$ years $(n=107,55.2$ per cent). This was followed by the age group of $46-55$ years, $(n=35,18.0$ per cent) then respondents aged between 25 -35 years ( $n=32,16.5$ per cent). In addition, respondents who were 56 years and above were the smallest number in terms of academic staff participation $(n=20$, 10.3 per cent).

Regarding respondents' race group, the analysis showed that the majority of the participants ( $n=99,51.0$ per cent) were Malay academic staff. Followed by foreign academic staff ( $n=78,40.2$ per cent). Indian academic staff $(n=10,5.2$ per cent) participated in the study as well as Chinese academic staff $(n=7,3.6$ per cent) who responded.

Regarding respondents' marital status, the data yielded that majority ( $n=172$, 88.7 per cent) of academic staff surveyed were married. This was followed by academic staff who were classified as unmarried ( $n=18,9.3$ per cent). Some $(n=3,1.5$ per cent) of the participants were classified as widowed and only $(n=1,0.5$ per cent) of them was identified as a divorcee.

The analysis demonstrated that the majority ( $n=187,96.4$ per cent) of the respondents, who participated in the study were Muslims. Followed by participants, who identified themselves as Buddhists $(n=4,2.1$ per cent). Both Hindu $(n=2$, 1.0 per cent) and Christian ( $n=1,0.5$ per cent) respondents were the smallest denominations represented in this study.

Table I shows that the majority ( $n=66,34.0$ per cent) of the respondents were assistant professors. Followed by the category of lecturers ( $n=61,31.4$ per cent). Associate professors $(n=29,14.9$ per cent) and professors $(n=23,11.9$ per cent) were the next largest groups of respondents. Senior lecturers were the least prominent among the respondents ( $n=15,7.7$ per cent).

In addition, Table I shows the majority of the respondents ( $n=40,20.6$ per cent) were teaching staff with teaching experience, which ranged between 11 to 15 years.

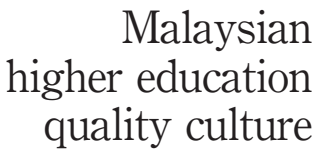

293 
QAE

20,3

\begin{tabular}{lcc}
\hline Variable & Frequency & Per cent \\
\hline Gender & & \\
Male & 109 & 56.2 \\
Female & 85 & 43.8 \\
Total & 194 & 100
\end{tabular}

294

Age group (years)

25-35

36-45

46-55

56 and above

Total

43.8

194

16.5

32

55.2

107

18.0

35

194

10.0

Race group

Malay

Chinese

Indian

Others

100

Total

51.0

99

7

10

78

194

3.6

5.2

40.2

Marital status

Unmarried

100

Married

Divorcee

Widowed

Total

18

172

9.3

1
3

194

88.7

0.5

Religion

Islam

Christianity

Hinduism

Buddhism

Total

100

Academic position

Lecturer

Senior Lecturer

Assistant Professor

Associate Professor

187

96.4

1

194

100

Professor

31.4

61

7.7

66

34.0

29

23

Total

11.9

Working experience (years)

1-5

6-10

11-15

16-20

21-25

26-30

31-35

Above 36

194

100

Total

37

19.1

31

16.0

40

20.6

36

19

18.6

18

9.8

9.3

2.6

5
8

194

4.1

Monthly income (RM)

Table I.

2,500-3,000

$3,001-7,500$

7,501-10,000

Above 10,000

100

Frequency and

Total

96

49.5

respondents'

19.1

12.5

24

194 
Respondents with teaching experience ranging between 1 to 5 years $(n=37$, 19.1 per cent) were next most frequent. Respondents with teaching experience, which ranged between 16 to 20 years $(n=36,18.6$ per cent) and those with 6 to 10 years' experience ( $n=31,16.0$ per cent) were next most frequent. Staff with 21 to 25 years' experience ( $n=19$, 9.8 per cent) participated in this study. Very experienced respondents with teaching experience of 26 to 30 years $(n=18,9.3$ per cent), above 36 years $(n=8,4.1$ per cent) and 31 to 35 years $(n=5,2.6$ per cent) made up the participants in this study.

Finally, the results in Table I showed that the majority ( $n=96,49.5$ per cent) of the respondents surveyed were earning a monthly income in the range of RM 3,001 to 7,500. Followed by respondents with monthly income of both RM 2,500 to 3,000 ( $n=37,19.1$ per cent) and RM 7,501 to $10,000(n=37,19.1$ per cent). Furthermore, respondents who earn above RM 10,000 monthly were the smallest group in the teaching staff surveyed $(n=24,12.5$ per cent).

\section{Principal components analysis (PCA)}

Reliability analysis was conducted to assess the internal consistency of the instruments. The results of reliability analysis revealed the overall coefficient alpha of 0.97 . This indicated a substantial internal consistency between individual items, thus the items have positive covariance and the alpha is very close to 1 (Abdullah, 2005; Leech et al., 2005; Abdullah, 2006; Abdullah et al., 2008). Furthermore, this finding indicated that the instruments were suitable and therefore their results would be reliable in association with internal consistency build up.

\section{Principal component analysis for quality culture}

PCA with varimax rotation was conducted for the construct of quality culture. The analyses involved an iterative process to reach the final solution, whereby the items that did not contribute significantly and practically to the factors extracted were automatically discarded. Furthermore, the factors with eigenvalues of 1 or greater were considered as good factors, and therefore retained. Given such a rule of thumb, a number of factors were extracted from the pool of items. The correlation matrix yielded more than two correlations greater than 0.30 . The measures of sampling adequacy (MSA) requirement of ( 0.50 or greater) were also satisfied. Thus, the anti-image correlation ranged between 0.78 and 0.93 . Furthermore, all communalities were greater than 0.50 (ranged between 0.58 to 0.86 ), which indicates fulfilment of this requirement.

Moreover, the analysis revealed ten interpretable factors: quality improvement, teamwork, customer focus, strategic planning for quality, recognition, top management support for quality, measurement and analysis, empowerment and involvement, quality training and quality assurance that underlie the quality culture with eigenvalues greater than one. The extracted factors accounted for 75.7 per cent of variance explained in the constructs analysed. Interestingly, the degree of inter-correlation among the items also reached satisfactory level. Bartlett's test of Sphericity was statistically significant $\chi^{2}(1830)=6350.440, \rho \leq .001, \mathrm{KMO}=0.862$.

\section{Principal component analysis for workforce performance}

Another PCA analysis with varimax rotation was performed on the workforce performance construct to determine the inter-relatedness of items of the factors 
QAE 20,3

296 constituting the construct. Three factors were initially hypothesised on this construct. The analysis generated four factors with eigenvalues greater than one. However, only two factors were retained. The omission of the other two factors was due to the factorial complexity or failure to meet fundamental practical significance of inclusion criteria (loading of 0.50 or greater). This finding resulted in H6 of the study being rejected.

As a result, the observation showed that the two factors extracted accounted for 68.9 per cent of the variance in workforce performance. Interestingly, the degree of inter-correlation among the items also reached an acceptable level, Bartlett's Test of Sphericity was statistically significant, $\chi^{2}(230)=1339.734, \rho \leq 0.001, \mathrm{KMO}=0.85$. The MSA, which does not determine the correlations between the items per se, but also structural patterns of the variables also ranged from 0.52 to 0.83 . In addition, all communalities were greater than 0.50 (ranged from 0.50 to 0.76 ), which indicates the fulfilment of the requirements of the rule of thumb.

\section{Instrument validation}

Given the fact that instrument validation was one of the objectives of this study, factors extracted through PCA were further rigorously validated through average variance extracted (AVE) and composite reliability index (CRI) for construct, convergent and discriminant validity.

\section{Quality culture subscales}

The alpha coefficient of quality culture subscales yielded substantial levels of internal consistency; meanwhile the scores of all factors have exhibited the recommended benchmark of coefficient alpha (0.70). The results show that alpha coefficient of nine factors extracted ranged from 0.83 to 0.94 . This finding affirmed that the subscales of quality culture are internally consistent and reliable.

Having established the internal consistency of quality culture subscales, the convergent validity was evaluated through the AVE method recommended by (Fornell and Larcker, 1981). The results show that the estimation of AVE for factors (quality improvement teamwork 0.53 , customer focus 0.51 , strategic planning for quality 0.50 , recognition 0.41 , top management support for quality 0.40 , measurement and analysis 0.46 , empowerment and involvement 0.43 , quality training 0.50 and quality assurance 0.40 respectively). The estimates $(0.50$ through 0.53$)$ fulfilled the recommended value of AVE (Fornell and Larcker, 1981). Though the estimates (0.40 through 0.46$)$ fell a little below the threshold value, they were very close to the recommended cut-off. These findings demonstrate the evidence of convergent validity for the quality culture subscales.

The construct validity of the scales was further assessed using the CRI method. According to Fornell and Larcker (1981), the evidence of construct validity is established if the CRI of each factor is 0.70 or greater. The results of CRI revealed substantial evidence of construct validity (0.71 through 0.84$)$. Table II provides the details.

The correlations among the quality culture constructs validated are presented in Table III. The constructs included in the analysis revealed reasonably high significant correlation among the variables under study. More specifically, the correlations ranged from $(r=0.34$ to $r=0.69, \rho \leq 0.001)$, with the relationship between top management 
support for quality correlated with empowerment and involvement $(r=0.69$, $\rho \leq 0.001)$, recognition with top management support for quality $(r=0.66$, $\rho \leq 0.001$ ), strategic planning for quality with empowerment and involvement $(r=0.63, \rho \leq 0.001)$, quality improvement teamwork with strategic planning for quality $(r=0.62, \rho \leq 0.001)$, recognition with empowerment and involvement $(r=0.61, \rho \leq 0.001)$ and quality improvement teamwork with quality assurance $(r=0.60, \rho \leq 0.001)$ exhibiting substantial significant and practical correlation values. Interestingly, all correlations were found to be positive and significant. Table III presents the details.

\section{Workforce performance subscales}

The internal consistency of workforce performance subscales was evaluated through coefficient alpha and was found to be substantial across the factors extracted based on Nunnally's (1978) recommended value of 0.70 or greater. The results indicated high internal consistencies for work performance $(\alpha=0.86)$ and job satisfaction $(\alpha=0.86)$ respectively. These findings showed that workforce performance subscales are internally consistent and reliable.

\begin{tabular}{lccc}
\hline Construct & $\alpha$ & AVE & CRI \\
\hline Quality improvement teamwork (QIT) & 0.88 & 0.53 & 0.81 \\
Customer focus (CF) & 0.89 & 0.51 & 0.80 \\
Strategic planning for quality (SPQ) & 0.94 & 0.50 & 0.84 \\
Recognition (REC) & 0.87 & 0.41 & 0.80 \\
Top management support for quality (TMSQ) & 0.88 & 0.40 & 0.77 \\
Measurement and analysis (MA) & 0.87 & 0.46 & 0.81 \\
Empowerment and involvement EI & 0.89 & 0.43 & 0.73 \\
Quality training (QT) & 0.83 & 0.50 & 0.75 \\
Quality assurance (QA) & 0.84 & 0.40 & 0.71 \\
\hline
\end{tabular}

\begin{tabular}{llllllllll}
\hline Construct & QIT & CF & SPQ & REC & TMSQ & MA & EI & QT & QA \\
\hline QIT & 1.00 & & & & & & & & \\
CF & $0.510^{*}$ & 1.00 & & & & & & & \\
SPQ & $0.625^{*}$ & $0.514^{*}$ & 1.00 & & & & & & \\
REC & $0.392^{*}$ & $0.487^{*}$ & $0.572^{*}$ & 1.00 & & & & & \\
TMSQ & $0.438^{*}$ & $0.494^{*}$ & $0.579^{*}$ & $0.662^{*}$ & 1.00 & & & & \\
MA & $0.291^{*}$ & $0.532^{*}$ & $0.546^{*}$ & $0.472^{*}$ & $0.478^{*}$ & 1.00 & & & \\
EI & $0.489^{*}$ & $0.579^{*}$ & $0.636^{*}$ & $0.610^{*}$ & $0.690^{*}$ & $0.570^{*}$ & 1.00 & & \\
QT & $0.345^{*}$ & $0.425^{*}$ & $0.438^{*}$ & $0.539^{*}$ & $0.579^{*}$ & $0.451^{*}$ & $0.529^{*}$ & 1.00 & \\
QA & $0.602^{*}$ & $0.369^{*}$ & $0.521^{*}$ & $0.405^{*}$ & $0.513^{*}$ & $0.484^{*}$ & $0.508^{*}$ & $0.407^{*}$ & 1.00
\end{tabular}

Notes: *Correlation is significant at the 0.01 level (two-tailed); QIT $=$ quality improvement teamwork, $\mathrm{CF}=$ customer focus, $\mathrm{SPQ}=$ strategic planning for quality, $\mathrm{REC}=$ recognition, $\mathrm{TMSQ}=$ top management support for quality, $\mathrm{MA}=$ measurement and analysis, $\mathrm{EI}=$ empowerment and involvement, $\mathrm{QT}=$ quality training, $\mathrm{QA}=$ quality assurance

\section{Malaysian higher education quality culture}

297 
QAE

20,3

298

The construct validity was then evaluated using the AVE method. The estimates (work performance 0.59 and job satisfaction 0.51 respectively) were greater than the recommended level 0.50 as proposed by (Fornell and Larcker, 1981). These results established the evidence that the convergent validity of workforce performance subscales prevailed. In addition, the CRI also produced substantial scores with the work performance construct returning a CRI of 0.87 and job satisfaction 0.87 values respectively. These results further confirm the construct validity of workforce performance subscales. Table IV illustrates the details.

The correlations among workforce performance constructs were then explored. Table V shows that the variables included were correlated. The degree of correlation between the variables work performance and job satisfaction was high.

\section{Measurement model}

The measurement model was assessed using AMOS prior to employing structural equation modelling or SEM (Arbuckle, 2008). A confirmatory factor analysis (CFA) with maximum likelihood was used to assess the nine-factor model of the quality culture construct. It allows an overall assessment of within and between the validity of indicators of the 9-factor model of quality culture. The following measures; Chi-square $\left(\chi^{2}\right)$, Relative non-Centrality Index (RNI), Comparative Fit Index (CFI), Turker-Lewin Index, and Root Mean Square Error of Approximation (RMSEA) with its point estimate and associated confidence $(\mathrm{CI})$ interval using the method of lower and upper bound of the CIs in combination with 0.05 and 0.10 as the cut-off values being used to validate the extent to which the hypothesised 9-factor model fits the data. When the RMSEA with its CIs are used, a given model is rejected if the lower bound of the CI is greater than the value of 0.05 . Similarly, a given model is rejected if the upper bound of the CI is greater than the value of 0.10 (Chen et al., 2008).

The initial results of the measurement model of the 9-latent exogenous variables demonstrated poor fit statistics; $\chi^{2}(370)=603.818, \quad$ CFI $=0.90$, TLI $=0.88$, $\mathrm{NNF}=0.78, \mathrm{RMSEA}=0.07$ and $\mathrm{CMIN} / \mathrm{DF}=1.63$. Although, the values of RMSEA, CMIN/DF and CFI fell within an acceptable range, the overall estimation of the model showed inadequate model fit. However, when the model was revised and three inter-correlations among six error terms were freed based on the suggestions of the parameters of modification indices (MIs), the model showed better fit. Given the

Table IV.

Construct reliability and validity of workforce performance subscales

\begin{tabular}{lccc}
\hline Construct & $\alpha$ & AVE & CRI \\
\hline Work performance (WP) & 0.86 & 0.59 & 0.87 \\
Job satisfaction (JS) & 0.86 & 0.51 & 0.87 \\
\hline
\end{tabular}

Table V.

Correlations between workforce performance subscales

\begin{tabular}{lcr}
\hline$\varrho$ & WP & JS \\
\hline Work performance & 1.00 & \\
Job satisfaction & $0.551^{*}$ & 1.00 \\
Note: *Correlation is significant at the 0.01 level (two-tailed) & \\
\hline
\end{tabular}


suggestions of the MIs, the following connections were made: errors 35 (Item EI 17) and 36 (Item EI 15), 5 (Item CF 32) and 43 (Item QA 44) and 9 (Item SPQ 60) 35 and (Item EI 17) respectively. As a result, the discrepancies declined and better model fit to the sample data was established. $\chi^{2}(376)=565.2, \mathrm{NFI}=0.90, \mathrm{CFI}=0.92$, TLI $=0.91$ and RMSEA $=0.072$ with 90 per cent confidence interval of 0.060-0.084. Moreover, CMIN/DF revealed a value of 1.5, which according to Schermellah-Engel et al. (2003), is indicative of better goodness-of-fit.

Furthermore, the factor loadings of indicator variables to factors are presented in Figure A1 (Appendix). All items of quality culture subscales show excellent factor loadings (> 0.70) (Comrey and Lee, 1992. Moreover, Table VI shows that all factor loadings were statistically significant. The standardised factor loadings are reported in the upper column, whereas fit indices are reported in lower columns.

The results of the 9-factor quality culture measurement model validated demonstrated a satisfactory factorial validity, suggesting that the core of the quality culture model could be best represented by three general factors (corporate characteristics of quality culture, quality culture improvement and quality culture development). In other words, the first-order factors could be indexed by most correlated factorial structures.

\section{Corporate characteristics of quality culture measurement model evaluation}

CFA was applied to test the adequacy of the measurement model. The adequacy of the measurement models was evaluated according to the criteria of model fit, convergent validity, and discriminant validity. The results of fit indices indicate that the measurement model of corporate characteristics of quality culture fit the sample data. The $\chi^{2}(30)=31.6$, NFI $=1.0, \mathrm{CFI}=1.0, \mathrm{TLI}=1.0$ and RMSEA $=0.023$ with its associated lower bound of $\mathrm{CI}$ reaching 0.001 and higher bound of $\mathrm{CI}$ reaching 0.079 , suggesting excellent satisfaction of the criteria (see Figure 1). Furthermore, the results of the discriminant validity also show that the structure factors are distinctive, except the squared inter-correlation between top management support for quality and empowerment and involvement factors, yet they hold discriminant validity since AVE of the factor is greater than 0.50 and CRI is greater than 0.70 (Kline, 2011). Table VII contains the details.

\begin{tabular}{lccccccccc}
\hline Item & QIT & CF & SPQ & REC & TMSQ & MA & EI & QT & QA \\
\hline 1 & 0.86 & 0.86 & 0.81 & 0.74 & 0.81 & 0.76 & 0.81 & 0.82 & 0.75 \\
2 & 0.81 & 0.87 & 0.84 & 0.80 & 0.81 & 0.80 & 0.73 & 0.88 & 0.92 \\
3 & 0.78 & 0.81 & 0.84 & 0.83 & 0.71 & 0.85 & 0.63 & 0.77 & 0.77 \\
4 & & 0.77 & 0.90 & 0.80 & & & & &
\end{tabular}

Notes: Goodness of fit criteria: $\chi^{2}=565.194 ; d f=367 ; \mathrm{NFI}=0.90 ; \mathrm{TLI}=0.91 ; \mathrm{CFI}=0.92$; RMSEA $=0.072 ; 90 \% \mathrm{CI}=0.060-0.084$; QIT $=$ quality improvement teamwork, $\mathrm{CF}=$ customer focus, $\mathrm{SPQ}=$ strategic planning for quality, $\mathrm{REC}=$ recognition, $\mathrm{TMSQ}=$ top management support for quality, $\mathrm{MA}=$ measurement and analysis, $\mathrm{EI}=$ empowerment and involvement, $\mathrm{QT}$ = quality training, QA = quality assurance

\section{Malaysian higher education quality culture}

\author{
299
}

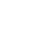


QAE

20,3

300

Figure 1.

Corporate characteristics of quality culture
Table VII.

Discriminant validity, composite reliability of corporate characteristic of quality culture construct

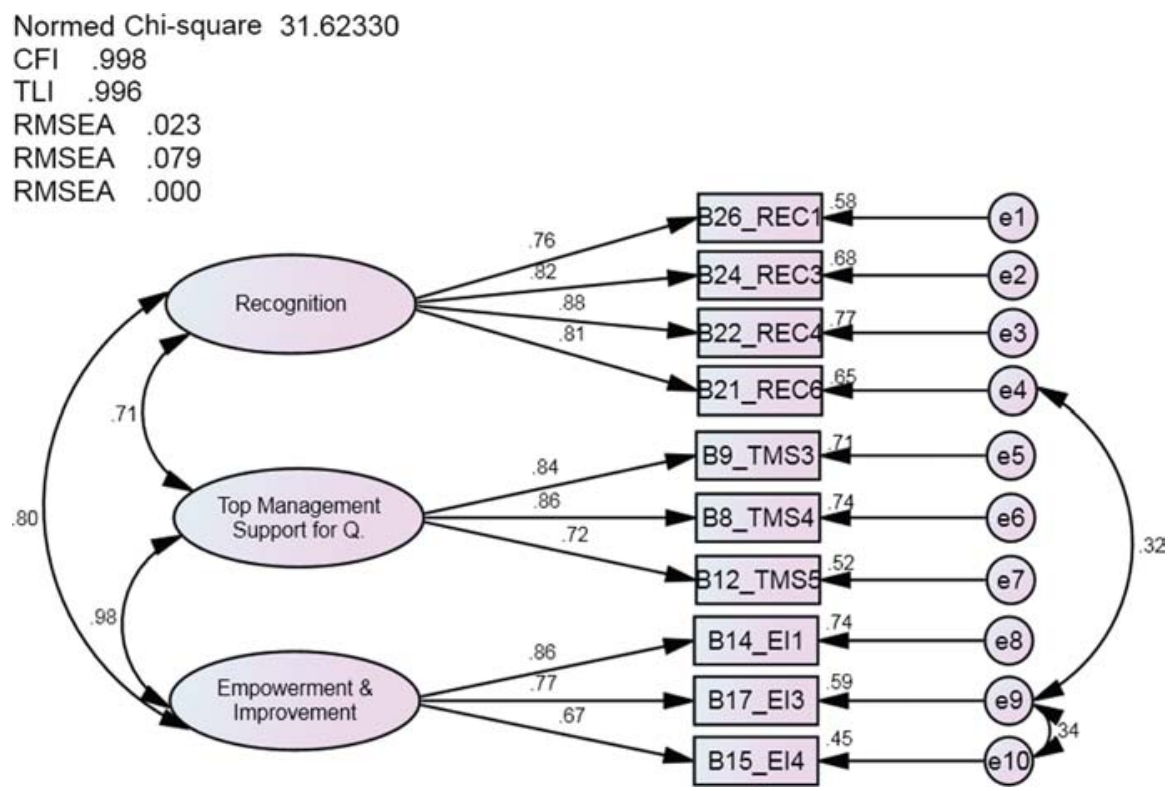

Quality culture improvement measurement model evaluation

Similarly, a CFA was performed to confirm the factor structure of the second model, which included the CF, MA and QT correlated to a single factor model of quality culture improvement. Interestingly, the fit indices indicated a very good fit to the sample data: $\mathrm{NFI}=0.98$ and $\mathrm{CFI}=1.0, \mathrm{TLI}=1.0$ and $\mathrm{CMIN} / \mathrm{DF}=1.3$. The RMSEA also showed an excellent fit: RMSEA $=0.050$ with 90 per cent confidence interval 0.001-0.094 (see Figure A2 (Appendix). The results of discriminant validity also show that the structures of the factors are distinctive, and squared inter-correlation between all factors yielded lower values compared to the AVE. Table VIII shows the details of the results.

Quality culture development measurement model evaluation

Finally the CFA of quality culture exogenous variable has also shown a good fit for the measurement model fit indices $\left(\chi^{2}=48.64, \mathrm{CFI}=0.97, \mathrm{TLI}=0.96, \mathrm{CMIN} / \mathrm{DF}=1.6\right.$

\begin{tabular}{lcccr}
\hline & \multicolumn{2}{c}{ AVE, Squared inter-factor correlation and CRI } & \\
Construct & Rec & TMSQ & EI & CRI \\
\hline Rec & $(0.67)$ & & & 0.89 \\
TMSQ & 0.50 & $(0.65)$ & & 0.85 \\
EI & 0.64 & 0.96 & $(0.64)$ & 0.84
\end{tabular}

Notes: $\quad$ Fit indices criteria: $\quad \chi^{2}=31.6 ; \quad d f=30 ; \quad$ NFI $=1.0 ; \quad$ TLI $=1.0 ; \quad$ CFI $=1.0$; RMSEA $=0.023 ; 90 \% \mathrm{CI}=0.001-0.079$; Diagonals in parentheses are square roots of the average variance extracted from observed variables (items), whereas off-diagonals are squared correlations between the constructs. $\mathrm{REC}=$ recognition, $\mathrm{TMSQ}=$ top management support for quality, $\mathrm{EI}=$ empowerment and involvement 
and RMSEA $=0.077$ with 90 per cent confidence interval 0.033-0.077 (see Figure A3 in Appendix), providing support pertaining to factorial construct validity of the assessed model. The results show the substantial evidence of discriminant validity pertaining to all constructs. This finding supported $H 5$ of the study. Table IX displays the details.

\section{Testing for factorial validity of second-order CFA}

A CFA was performed to test the factorial validity of the quality culture second-order model. The results showed moderately acceptable model fit. The analysis revealed fit statistics in which $\chi^{2}(395)=597.8, \quad$ CFI $=0.91, \quad$ TLI $=0.90, \quad$ NFI $=0.89$, $\mathrm{CMIN} / \mathrm{DF}=1.5$ and $\mathrm{RMSEA}=0.070$ with its associated 90 per cent confidence interval that the lower bound $=0.059$, higher bound $=0.081$ yielded satisfactory values. Although, the lower bound of RMSEA related CI in model rejection was close to the threshold value, it did not exceed the threshold value (0.05).

However, the model was re-estimated for better fit. As such, two inter-correlations among four error terms were freed based on the suggestions of the parameters of the MIs. Errors 5 (Item TMS3) and 19 (Item QT2) and 11 (Item CF 1) and 30 (Item QA 44) were correlated. As a result, the model demonstrated a better model fit to the sample data. The $\chi^{2}(393)=568.933, \mathrm{NFI}=0.89, \mathrm{CFI}=0.92, \mathrm{TLI}=0.91$ and $\mathrm{RMSEA}=0.066$ with 90 per cent confidence interval of 0.053-0.077 showed better improvement pertinent to goodness-of-fit. Furthermore, CMIN/DF had a value of 1.4, which according to Schermellah-Engel et al. (2003), is indicative of a good fit. Figure 2 displays the details. This finding supported $H 4$ of the study.

\begin{tabular}{|c|c|c|c|c|}
\hline \multicolumn{5}{|c|}{ AVE, Squared inter-factor correlation and CRI } \\
\hline Construct & $\mathrm{CF}$ & MA & QT & CRI \\
\hline $\mathrm{CF}$ & $(0.50)$ & & & 0.91 \\
\hline MA & 0.30 & $(0.67)$ & & 0.86 \\
\hline QT & 0.26 & 0.25 & $(0.71)$ & 0.88 \\
\hline
\end{tabular}

Notes: Fit indices criteria: $\chi^{2}=39.1 ; d f=31$;FI $=0.98$; TLI $=1.0$; CFI $=1.0$; RMSEA $=0.050$; $90 \% \mathrm{CI}=0.001-0.094$; Diagonals in parentheses are square roots of the average variance extracted from observed variables (items), whereas off-diagonals are squared correlations between the constructs. $\mathrm{CF}=$ customer focus, $\mathrm{MA}=$ management and analysis, $\mathrm{QT}=$ quality training

\section{Malaysian higher education quality culture}

301

\begin{tabular}{lcccr}
\hline & \multicolumn{2}{c}{ AVE, Squared inter-factor correlation and CRI } & \\
Construct & SPQ & QIT & QA & CRI \\
\hline SPQ & $(0.72)$ & & & 0.91 \\
QIT & 0.46 & $(0.79)$ & & 0.92 \\
QA & 0.49 & 0.44 & $(0.67)$ & 0.86
\end{tabular}

Notes: Fit indices criteria: $\chi^{2}=48.64 ; \quad d f=30 ; \quad \mathrm{NFI}=0.96 ; \quad \mathrm{TLI}=0.96 ; \quad \mathrm{CFI}=0.97$; RMSEA $=0.077 ; 90 \% \mathrm{CI}=0.033-0.116$; Diagonals in parentheses are square roots of the average variance extracted from observed variables (items), whereas off-diagonals are squared correlations between the constructs. SPQ = strategic planning for quality, QIT = quality improvement teamwork, $\mathrm{QA}=$ quality assurance

Table IX. Discriminant validity, composite reliability of quality culture development construct
Discriminant validity, composite reliability of quality culture improvement construct 
QAE

20,3

302

Figure 2.

Fit indices of the hypothesised model of quality culture second-order CFA

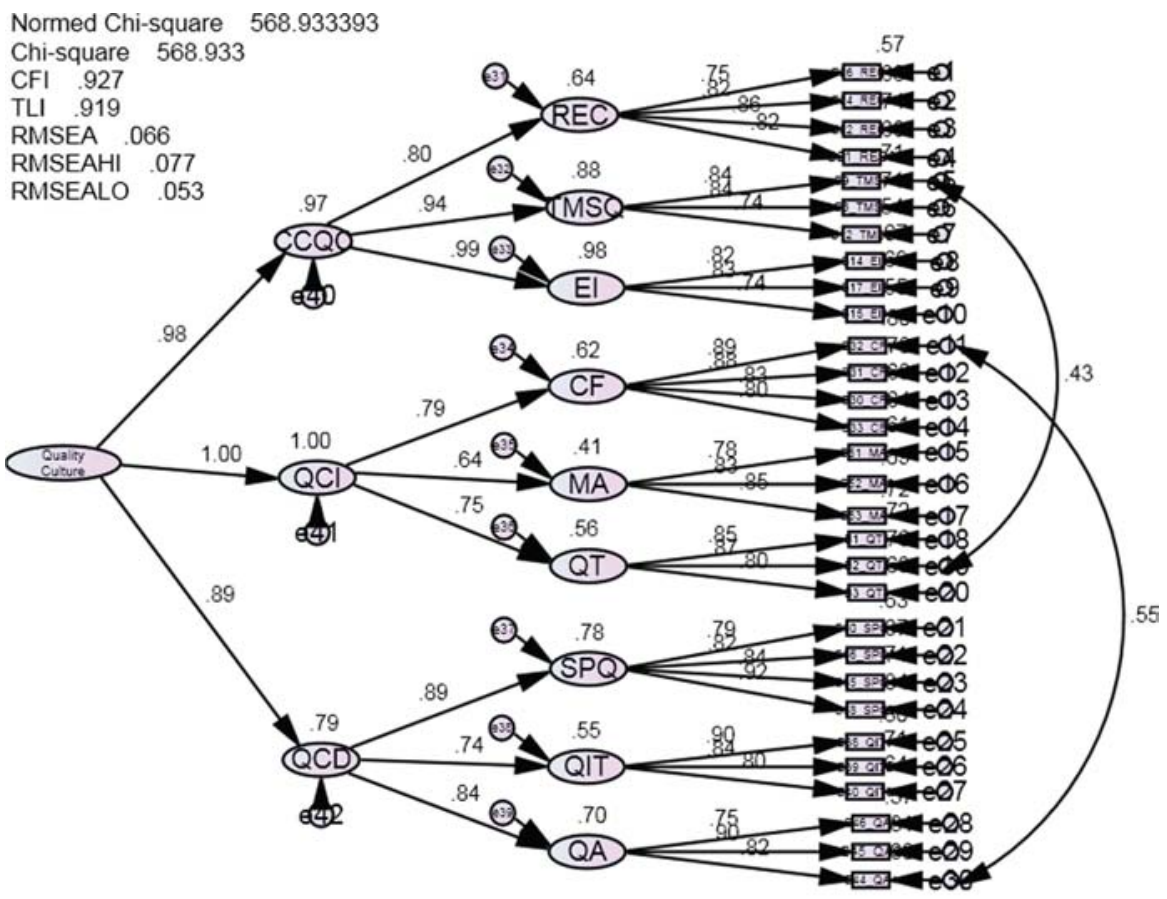

Notes: $\mathrm{CCQC}=$ corporate characteristics of quality culture, $\mathrm{QCI}=$ quality culture improvement, $\mathrm{QCD}=$ quality culture development, $\mathrm{REC}=$ recognition,

TMSQ = top management support for quality, EI = empowerment and involvement, $\mathrm{CF}=$ customer focus, $\mathrm{MA}=$ management and analysis, $\mathrm{QT}=$ quality training,

$\mathrm{SPQ}=$ strategic management for quality, QIT = quality improvement teamwork and

$\mathrm{QA}=$ quality assurance

\section{Workforce performance measurement model evaluation}

Another CFA was performed to assess the workforce performance measurement model. The items were subjected to a CFA with a four-factor (job satisfaction and work performance) measurement model using maximum likelihood estimation. The fit statistics showed a poor fit model to the sample data; $\chi^{2}(395)=192.696$, CFI $=0.88$, $\mathrm{TLI}=0.85, \mathrm{NFI}=0.86, \mathrm{CMIN} / \mathrm{DF}=2.4$ and $\mathrm{RMSEA}=0.118$ with 90 per cent confidence interval of 0.092-0.144 portrayed less goodness-of-fit. However, when the model was re-estimated with two items (Item JS3, "I am satisfied with benefits offered to me through this work culture", and Item JS6, "I have ample opportunities for advancement in this position") from job satisfaction construct and one item (WP4, "I always feel like spending extra effort in carrying out my job") from the work performance construct were omitted, and one error connection between e6 (Item, WP 1) and e11(Item, WP 4) was made, the results showed excellent model fit. The analysis revealed fit statistics in which $\chi^{2}(25)=33.006, \mathrm{CFI}=0.98$, TLI $=0.97$, NFI $=0.98$, $\mathrm{CMIN} / \mathrm{DF}=1.3$ and RMSEA $=0.055$ with its associated 90 per cent confidence interval that the lower bound $=0.001$, upper bound $=0.102$ yielded satisfactory values. Although, the higher bound of RMSEA related CI in model rejection slightly 
exceeded the threshold, it was supported by other fit indices that exhibited excellent values. Furthermore, the factor loadings ranged from 0.54 to 0.90 indicating the evidence of statistical significance (see Figure 2 in Appendix).

Next, CRI for each construct was calculated. The constructs had shown substantial levels of CRI, ranging from 0.84 to 0.86 . Moreover, the convergent validity of the construct was evaluated through the AVE method. The two constructs provided evidence of convergent validity, in which job satisfaction construct exhibited an AVE value of 0.51, and work performance construct demonstrated an AVE value of 0.50. These values ( 0.50 or greater) according to Fornell and Larcker (1981), provide evidence of convergent validity. In addition, discriminant validity was finally assessed through comparing AVE values with squared inter-factor correlation. The results revealed that the AVE values greater than squared values of inter-factor correlations, indicating evidence of discriminant validity (Fornell and Larcker , 1981). These results revealed that $H 7$ is accepted with the finding that constructs of job satisfaction and work performance are distinct, valid and reliable. Table X displays the results.

\section{Determinants of workforce performance}

Model estimation with structural equation modelling (SEM) test was performed to validate the hypothesised model as well as investigating the relationship between quality culture and workforce performance with special reference to the Malaysian higher education sector. According to the hypothesised model, quality culture determines academic staff's work performance and job satisfaction. Nine exogenous variables included in the model were measured using summated indicator variables ranged from 3 to 4 items. Similarly, two endogenous variables included in the hypothesised model were also measured by summated indicator variables ranged from 4 to 5 items per construct. This summation was done to reduce the complications of the model especially when the model contains many variables. It is also equally done to represent multiple aspects of a concept in a single measured variable.

The results of the overall model estimation showed a good fit of the hypothesised model to the sample data. The analysis revealed excellent fit statistics; $\chi^{2}(43)=49.91$, $\mathrm{CFI}=0.98, \quad \mathrm{TLI}=0.97, \quad \mathrm{NFI}=0.98, \quad \mathrm{CMIN} / \mathrm{DF}=1.16 \quad$ and $\mathrm{RMSEA}=0.053$. Moreover, the $\rho \leq 0.218$ was found to be insignificant, which is indicative of goodness of model fit. In addition, the model also exhibited the standardised solution coefficients through the use of Maximum Likelihood command which were found to be substantial. Interestingly, all summated coefficient scores were found to be statistically significant, ranging from 0.60 (quality assurance factor) to 0.93 (empowerment and

\begin{tabular}{|c|c|c|c|}
\hline \multicolumn{4}{|c|}{ AVE, Squared inter-factor correlation and CRI } \\
\hline Construct & Job satisfaction & Work performance & CRI \\
\hline Job satisfaction & $(0.51)$ & & 0.84 \\
\hline Work performance & 0.43 & $(0.50)$ & 0.86 \\
\hline
\end{tabular}

Notes: Fit indices criteria: $\chi^{2}=33.006 ; \quad d f=25 ; \quad \mathrm{NFI}=0.98 ; \quad \mathrm{TLI}=0.96 ; \quad \mathrm{CFI}=0.98$; RMSEA $=0.055 ; 90 \% \mathrm{CI}=0.001-0.102$; Diagonals in parentheses are square roots of the average variance extracted from observed variables (items), whereas off-diagonal is squared correlations between the constructs

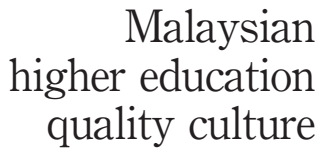

303

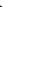


QAE

20,3

304

improvement factor) for exogenous variables and from 0.57 to 0.96 for endogenous variables. These findings supported the goodness of the model fit. It is also worth noting that all path coefficients in the hypothesised model were positive and statistically significant. The model explains relatively moderate percentage of the dependent variable; 0.26 per cent of workforce performance. The model also revealed correlation coefficient value greater than 0.50 between quality culture construct and workforce performance construct $(r=0.51)$. This clearly provides evidence that the causal relationship between the exogenous and endogenous variables exists, and Figure 3 presented the detailed results. These results indicate acceptance of $H 2$ and $H 3$ with the findings that quality culture has positive causal influence on both job satisfaction and work performance in the Malaysian higher education sector. The results however, indicate rejection of $H 1$ with the finding that workforce performance construct in Malaysian higher education context is indexed by two factor components rather than three.

\section{Discussion and conclusion}

Ultimately, this study aimed at investigating the psychometric properties and causal relationship between quality culture (QC) and workforce performance (WFP). The dimensionality of the $\mathrm{QC}$ construct in the context of the Malaysian higher education sector was examined. More importantly, the study shows evidence of psychometric properties validity of the scales and extended the limited research on QC

Figure 3.

Workforce performance measurement model

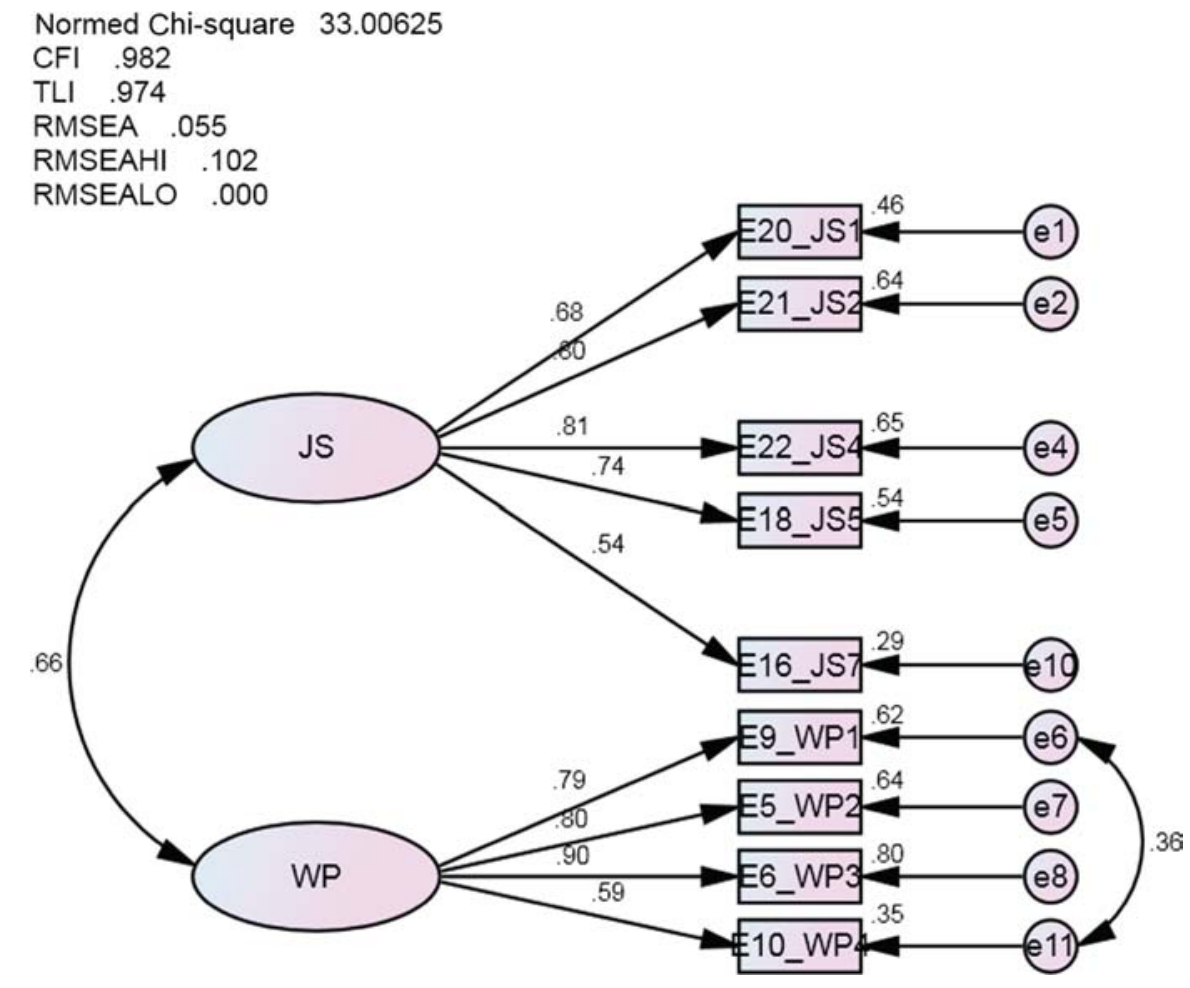


subscales, especially in the context of the higher education sector. The overall model for QC subscales suggested by Johnson (2000) and Tungkunanan et al. (2008) demonstrated a general goodness-of-fit for the sample from the Malaysian higher education sector.

The first-order 9-factor CFA model of QC construct supported the hypothesis that $\mathrm{QC}$ is indexed by nine measured factors. The findings revealed that the data for the International Islamic University Malaysia faculty members were best represented by nine structured observed factors and high second-order 4-factor model. The findings also revealed that the validity of the psychometric properties, structural and measurement model were established. Thus, the analysis supported the conceptual design of the scales since reliability, convergent, construct and discriminant validity of scales were maintained.

Furthermore, by employing structural equation modelling, the causal relationship between QC and WFP was found to be substantial, suggesting that QC leads to high job satisfaction and work performance among the academic staff surveyed. The findings were in keeping with Adebanjo and Kehoe (1999) who found companies that practiced and implemented a quality culture experienced high workforce performance and organisational excellence compared to companies which are not $\mathrm{QC}$ oriented. Moreover, the findings were also congruent with Harvey (2009) who reached the conclusion that QC strongly determines quality of teaching experienced by faculty members of the institution of higher learning investigated. The pattern discovered was that when the university establishes a QC oriented workplace the academic staff are more likely to be satisfied with the nature of their academic professional life, therefore work constructively for the cause of organisational success.

In addition, the findings of the study have some practical implications for quality related initiatives pertaining to the nature and structure of $\mathrm{QC}$ in the context of the higher education sector. More specifically, the findings suggested that $\mathrm{QC}$ could enrich instructional effectiveness and improved workforce performance with special reference to quality management practices at the case university in particular and perhaps other institutions of higher learning more generally. It could be used as an effective instrument (through occasional quality training workshops) to stimulate the workforce at institutions of higher learning to engage in effective and creative instructional activities that are associated with their professional background. Finally, the findings provide psychometric validity and reliability of the instruments pertaining to quality improvement in the context of the Malaysian higher education sector.

\section{Limitation and future research}

A major limitation of this study may be the use of convenience sampling. Although it is appropriate for an exploratory study, one must regard the results obtained in this study as preliminary research findings. A replication of the study with a more systematic, probability-based sample would provide greater empirical support for the findings described above, and is strongly advised. More effort is needed to examine and replicate the study using larger samples and more institutions of higher learning. 
QAE

20,3

306

\section{References}

Abdullah, F. (2005), "HEdPERF versus SERVPERF: the quest for measuring instrument of service quality in higher education sector", Quality Assurance in Education, Vol. 13 No. 4, pp. 305-28.

Abdullah, F. (2006), "Measuring service quality in higher education: HEdPERF versus SERFPERF", Marketing Intelligence and Planning, Vol. 24 No. 1, pp. 31-47.

Abdullah, F., Alwi, M.R., Lee, N. and Ho, V.B. (2008), "Measuring and managing franchisee satisfaction: a study of academic franchising", Journal of Modelling in management, Vol. 3 No. 2, pp. 182-99.

Adebanjo, D. and Kehoe, D. (1999), "An investigation of quality culture development in UK industry", International Journal of Operations \& Production Management, Vol. 19 No. 7, pp. 633-49.

Arbuckle, J.L. (2008), AMOS 17.0 User's Guide, AMOS Development Corporation, Crawfordville, FL.

Bowen, P.W. (1996), “The need for quality cultures”, Training for Quality, Vol. 4 No. 2, pp. 14-18.

Chen, F., Curran, P.J., Bollen, K.A., Kirby, J. and Paxton, P. (2008), "An empirical evaluation of the use of fixed cut-off points in RMSEA tests statistic in structural equation models", Sociological Methods and Research, Vol. 36 No. 4, pp. 462-94.

Comrey, A.L. and Lee, H.B. (1992), A First Course In Factor Analysis, 2nd ed., Erlbaum, Hillsdale, NJ.

Crosby, P.B. (1979), Quality is Free, New American Library, New York, NY.

Deming, W.E. (1986), Out of the Crisis, Massachusetts Institute of Technology, Cambridge, MA.

Diana, G. (1994), What is Quality in Higher Education?, Society for Research into Higher Education, London.

Ehlers, U.D. (2009), "Understanding quality culture", Quality Assurance in Education, Vol. 17 No. 4, pp. 343-63.

European University Association (2002-2006), Quality Culture in European Universities. Report on the Three Rounds of the Quality Culture Project 2002-2006, European University Association (EUA), Brussels, available at: available at: www.eua.be/eua/jsp/en/upload/ Quality_Culture_2002_2003.1150459570109.pdf (accessed May 12, 2009).

Fornell, C. and Larcker, D.F. (1981), "Evaluating structural equation models with unobservable variables and measurement error", Journal of Marketing Research, Vol. 18 No. 1, pp. 39-50.

Harvey, L. (2009), “A critical analysis of quality culture”, International Network for Quality, available at: www.inqaahe.org/admin/files/assets/subsites/1/documenten/1241773373_ 16-harvey-a-critical-analysis-of-quality-culture.pdf (accessed March 23, 2010).

Horn, C.E.V. and Fichtner, A.R. (2003), "An evaluation of state-subsidised, firm-based training: the workforce development partnership programme", International Journal of Manpower, Vol. 24 No. 1, pp. 97-110.

Johnson, J.J. (2000), "Differences in supervisor and non-supervisor perceptions of quality culture and organisational climate", Public Personnel Management, Vol. 29 No. 1, ProQuest Education Journals, 199.

Juran, J. (1988), Juran on Planning for Quality, Free Press, New York, NY.

Kline, R.B. (2011), Principles and Practices of Structural Equation Modelling, 3rd ed., Guilford Press, New York, NY.

Kowalkiewicz, A. (2006), "The impact of quality culture on quality of teaching: a case study of business higher education in Poland", paper presented at the Conference of European 
University Association on Embedding Quality Culture in Higher Education, Technische Universität München, Munich, 23-25 November.

Leech, N.L., Barrett, K.C. and Morgan, G.A. (2005), SPSS for Intermediate Statistics Use and Interpretation, Lawrence Erlbaum Associates, Mahwah, NJ.

Meyers, L.S., Gamst, G. and Guarino, A.J. (2006), Applied Multivariate Research: Design And Interpretation, Sage Publications, London.

Miller, W.C. (1993), Quantum Quality: Quality Improvement through Innovation, Learning And Creativity, Quality Resources, White Plains, NY.

Muresan, L. (2008), "Promoting a quality culture at grassroots levels in higher education", Journal of Theoretical and Applied Economics, Vol. 12 No. 4.

Newton, J. (2006), "What is quality?", paper presented at the Conference of European University Association on Embedding Quality Culture in Higher Education, Technische Universität München, Munich, Germany, 23-25 November.

Nunnally, J.C. (1978), Psychometric Theory, McGraw-Hill, New York, NY.

Papis, J. (2006), "Understanding the workforce: the key to success in a youth hostel in Scotland", International Journal of Contemporary Hospitality Management, Vol. 18 No. 7, pp. 593-600.

Schermellah-Engel, K., Moosbrugger, H. and Müller, H. (2003), "Evaluating the fit of structural equation models: test of significance and descriptive goodness-of-fit measures", Methods of Psychological Research, Vol. 8 No. 2, pp. 23-74, available at: www.uni-frankfurt.de/ $\sim$ kscherm/schermelleh/mpr_Schermelleh.pdf (accessed May 28, 2011).

Sinclair, J. and Collins, D. (1994), “Towards a quality culture?”, International Journal of Quality and Reliability Management, Vol. 11 No. 5, pp. 19-29.

Tabachnick, B.G. and Fidell, L.S. (2007), Using Multivariate Statistics, Allyn and Bacon, Needham Heights, MA.

Trewin, D. (2003), “The importance of a quality culture", Quality Control and Applied Statistics, Vol. 48 No. 6, pp. 633-4.

Tungkunanan, P., Leekichwatana, P., Pimsarn, N. and Chumnun, S. (2008), "Strategic plan for developing quality culture at Eastern School of the Office of Vocational Education Commission, Thailand", ABAC Journal, Vol. 28 No. 2, pp. 52-63.

Vettori, J., Lueger, M. and Knassmuller, M. (2006), "Dealing with ambivalences - strategic options for nurturing a quality culture in teaching and learning". paper presented at the Conference of European University Association on Embedding Quality Culture in Higher Education, Technische Universität München, Munich, 23-25 November.

Vockell, E.L. and Asher, J.W. (1998), Educational Research, 2nd ed., Prentice Hall, Englewood Cliffs, NJ.

Yamane, T. (1967), Statistics: An Introductory Analysis, 2nd ed., Harper \& Row, New York, NY.

\section{Further reading}

Ferguson, G.A. (1981), Statistical Analysis in PhD Education, 5th ed., McGraw-Hill, New York, NY.

\section{Malaysian higher education quality culture}


QAE

20,3

308

Figure A1.

General CFA of quality culture 9-factor model

Figure A2.

Quality culture

improvement model

\section{Appendix}

$\begin{array}{rr}\text { Normed Chi-square } & 541.822368 \\ \text { CFI } & .915 \\ \text { TLI } & .900 \\ \text { RMSEA } & .076 \\ \text { RMSEAHI } & .089 \\ \text { RMSEALO } & .062\end{array}$

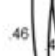

.062

Normed Chi-square 39.14731

$\begin{array}{lll}\text { CFI } & .987 & \\ \text { TLI } & .982 & \\ \text { RMSEA } & .050 \\ \text { RMSEAHI } & .094 \\ \text { RMSEALO } & .000\end{array}$

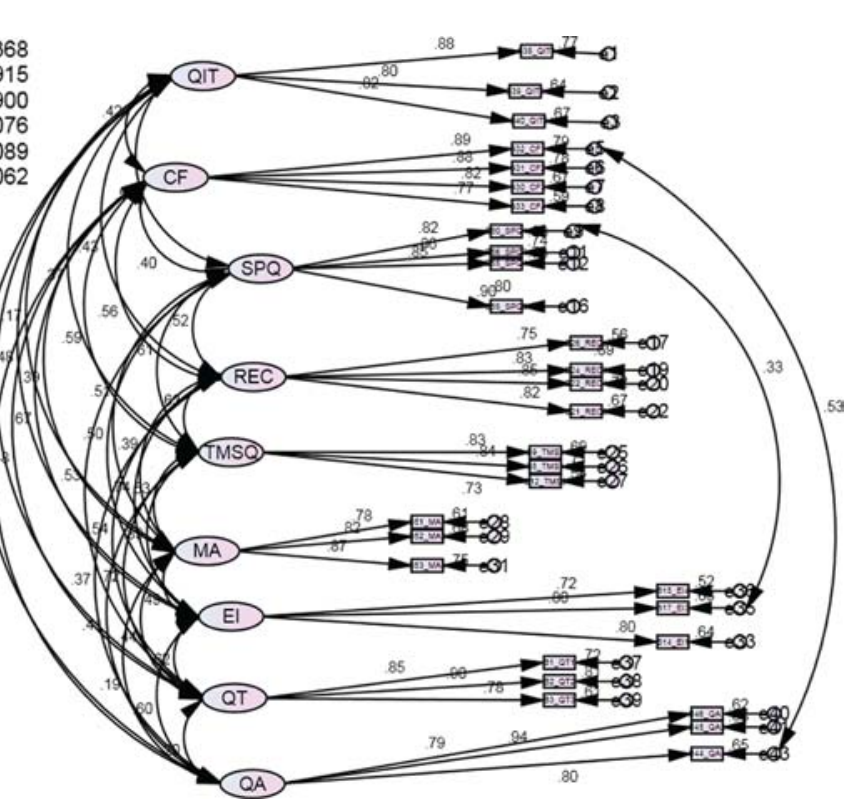

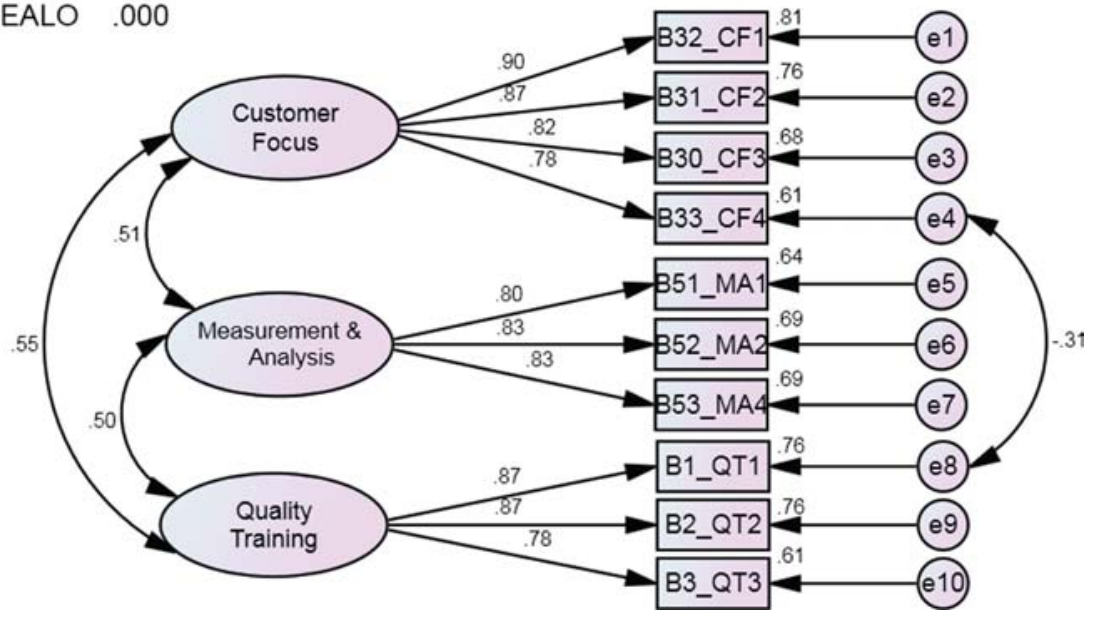



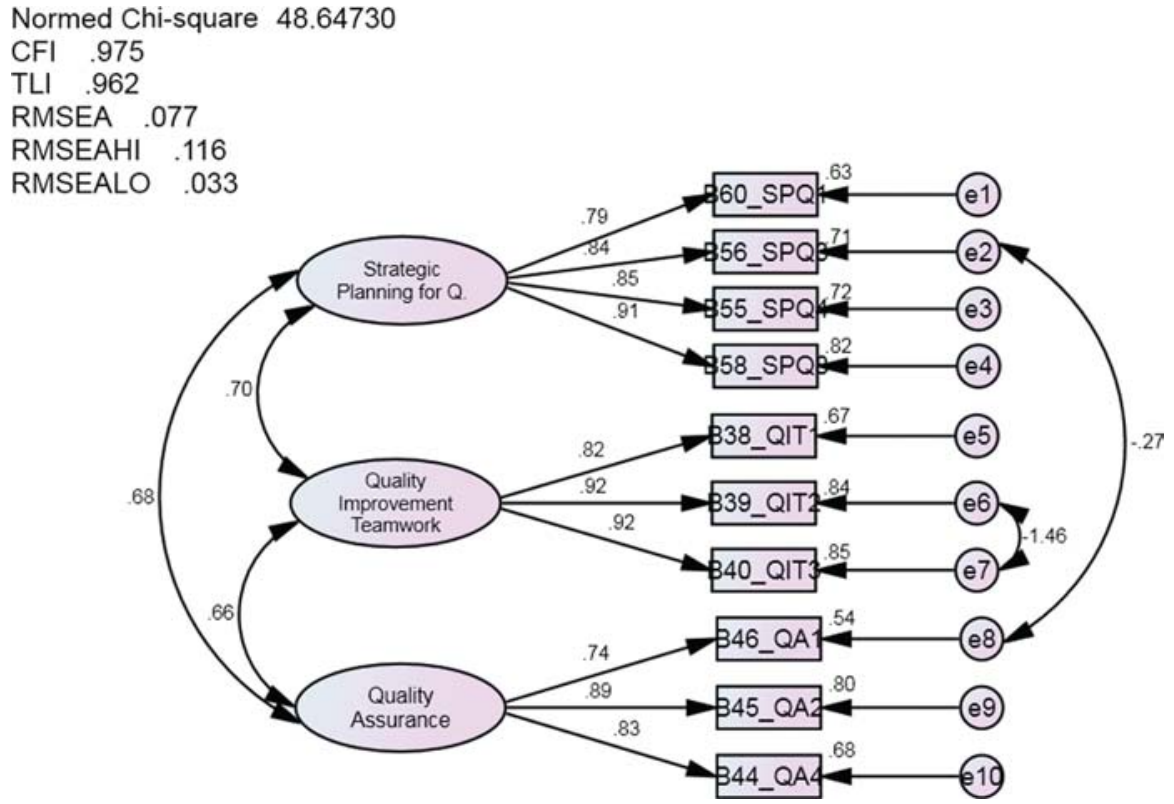

Malaysian higher education quality culture 309

\section{About the authors}

Hairuddin Mohd Ali is a lecturer at the International Islamic University Malaysia. He lectures in the area of educational management and leadership. Hairuddin Mohd Ali is the corresponding author and can be contacted at: hairuddin@iab.edu.my

Mohammed Borhandden Musah is from Ghana. He is now pursuing his $\mathrm{PhD}$ at the International Islamic University Malaysia in the area of educational management and leadership.

To purchase reprints of this article please e-mail: reprints@emeraldinsight.com Or visit our web site for further details: www.emeraldinsight.com/reprints 